\title{
EHMTI-0301. Effect of experimental tooth clenching on the release of beta-endorphin
}

\author{
A Dawson ${ }^{1 *}$, L Ljunggren ${ }^{2}$, M Ernberg ${ }^{3}$, P Svensson ${ }^{4}$, T List $^{1}$ \\ From 4th European Headache and Migraine Trust International Congress: EHMTIC 2014 \\ Copenhagen, Denmark. 18-21 September 2014
}

\section{Introduction}

Several etiologic factors have been suggested for tooth grinding and clenching, but the exact mechanism is not known. One biologic explanation might be that tooth clenching activates the reward system as observed in other types of muscle exercises

\section{Aims}

To investigate the association between experimental tooth clenching and the release of $\beta$-endorphin in patients with myofascial temporomandibular disorders (M-TMD) and healthy subjects.

\section{Methods}

Fifteen M-TMD patients and 15 healthy subjects were included and assigned an experimental clenching-task. Venous blood was collected and pain intensity was noted on a visual analog scale. The masseter pressure pain threshold (PPT) was assessed 2-hours before the clenching-task and immediately after. A mixed-model analysis of variance was used for statistical analyses.

\section{Results}

Significant main effects for time and group were observed for pain intensity and PPT, with a significantly higher pain intensity $(\mathrm{P}<.001)$ and a significantly lower PPT $(\mathrm{P}<.01)$ after the clenching-task compared with baseline. M-TMD patients had significantly higher pain intensity $(\mathrm{P}<.001)$ and significantly lower PPT $(\mathrm{P}<.05)$ than healthy subjects. No significant time or group effects were observed for the level of $\beta$-endorphin. Neither pain intensity nor PPT correlated significantly with $\beta$-endorphin levels.

'Department of Orofacial Pain and Jaw Function, Faculty of Odontology Malmö University, Malmö, Sweden

Full list of author information is available at the end of the article

\section{Conclusions}

This experimental clenching-task was not associated with significant alterations in $\beta$-endorphin levels over time, but with mechanical hyperalgesia and low to moderate levels of pain in healthy subjects and M-TMD patients, respectively. More research is required to understand the role of the $\beta$-endorphinergic system in the etiology of M-TMD.

No conflict of interest.

\section{Authors' details}

${ }^{1}$ Department of Orofacial Pain and Jaw Function, Faculty of Odontology Malmö University, Malmö, Sweden. ²Department of Biomedical Laboratory, Faculty of Health Sciences Malmö University, Malmö, Sweden. ${ }^{3}$ Section of Orofacial Pain and Jaw Function, Department of Dental Medicine Karolinska Institutet, Huddinge, Sweden. ${ }^{4}$ Section of Clinical Oral Physiology,

Department of Dentistry Aarhus University and Center for Functionally Integrative Neuroscience (CFIN) MindLab Aarhus University Hospital, Aarhus, Denmark.

Published: 18 September 2014

doi:10.1186/1129-2377-15-S1-C13

Cite this article as: Dawson et al:: EHMTI-0301. Effect of experimental tooth clenching on the release of beta-endorphin. The Journal of Headache and Pain 2014 15(Suppl 1):C13.

Submit your manuscript to a SpringerOpen ${ }^{\circ}$ journal and benefit from:

- Convenient online submission

- Rigorous peer review

- Immediate publication on acceptance

- Open access: articles freely available online

- High visibility within the field

- Retaining the copyright to your article

Submit your next manuscript at $>$ springeropen.com

\section{SpringerOpen ${ }^{\circ}$}

(C) 2014 Dawson et al; licensee Springer. This is an Open Access article distributed under the terms of the Creative Commons Attribution License (http://creativecommons.org/licenses/by/2.0), which permits unrestricted use, distribution, and reproduction in any medium, provided the original work is properly cited. 